\title{
E-Teaching in E-Workplaces: The Affective Nexus
}

\author{
doi:10.3991/ijac.v3i1.998 \\ K. McIntosh \\ University of Aberdeen, Aberdeen, Scotland
}

\begin{abstract}
This article outlines a small-scale phenomenological study of e-teachers' experience of feelings about and while discharging professional responsibilities in online workplaces, i.e. wherever a teacher is located while teaching the online components of either blended and wholly online teaching. In this paper the term blended refers to courses characterized by online teaching and learning as well as by face-to-face methods. Findings indicate that e-teachers' consciousness of positive feelings is associated with enhanced self-perception of well-being and increased engagement in eteaching, but that e-teachers are also conscious of feelings of disempowerment, isolation, vulnerability and frustration about and while working in e-workplaces. Findings also suggest that negative feelings impact detrimentally their sense of self as e-teachers, their participation in e-courses, their choice of e-teaching strategies, their interactions with e-learners and their self-efficacy as e-teachers. This in turn suggests an affective nexus in being e-teachers and interacting as e-teachers. The significance of this affective nexus for e-teachers' learning and continuing professional development is identified, and implications for those charged with overall responsibility for management of workplace conditions, workplace culture and employee well-being, as well as employee learning and professional development, are presented.
\end{abstract}

Index Terms-emotions, e-teaching, e-workplaces, phenomenology.

\section{INTRODUCTION}

In the pursuit of both corporate and academic goals, while it is entirely necessary to turn the researcher's gaze to the many factors that identify, promote or inhibit elearning in workplaces, it is equally necessary to examine the factors that impact e-teaching in workplaces. It is my belief that e-teaching has been under-researched and that the relationship of e-teachers' emotions and feelings with their work as e-teachers warrants particular investigation. A distinction between emotions and feelings is central to the research reported here: emotions are public and outwardly directed whereas feelings are private and inwardly directed. In other words, feelings are mental experiences of emotions [1].

The context of my enquiry lies partly in personal experience and partly in research literature. Over a ten-year career as an e-teacher working across a wide range of blended courses I have made extensive use of computerconnected technologies to discharge professional responsibilities and my experiences have been both affective and cognitive. For example, I have experienced profound satisfaction at having prompted high quality online enquiry and humour on the part of many of my e-learners; I have experienced simmering frustration at some e-learners' apparent reluctance to interact with others in the online learning environment thus flying in the face of the principles of social constructivism on which the design of my ecourses have been founded; and I have experienced isolation and vulnerability at having to carry, entirely on my own, the responsibility for everything related to my ecourses.

My mixed feelings as an e-teacher however, are not confined to the 'what' of my e-teaching. Regarding the 'where' of my e-teaching, while I have access to classrooms in which I can occasionally meet face-to-face with my e-learners, and an office that offers familiarity, the security of a regular structure to the times and places of my working day, storage for resources and proximity to the photocopier around which many social interactions with colleagues take place, my workplace is mainly situated elsewhere: my home, in hotels, in airports, on trains, in educational establishments; anywhere, in fact, that internet-connected communications can be accessed and interactions with e-learners facilitated as I travel attending to other aspects of my work as a teacher educator working in Higher Education. My e-teaching therefore, has been undertaken in e-workplaces distributed across many and diverse temporary, flexible and shifting locations that have often afforded little by way of ownership. I have certainly had very mixed feelings, often intense and enduring, about the 'any time, any place' characteristics of e-teaching.

The significance of these autobiographical details is that, having recently embarked on a sustained period of reflection on my ten-year career as an e-teacher and on the diverse workplace conditions that have framed my eteaching over that period, I have a strong suspicion that I may have allowed my feelings about myself as an eteacher, about my interactions with others as an e-teacher and about my consciousness of disparate e-workplace conditions to shape, in ways that I may not be fully conscious of, my e-teaching strategies, my demeanour with elearners, my decisions about what to say and how to say it and, ultimately, my effectiveness as an e-teacher. This suspicion has prompted a curiosity about its grounds and about how pervasive those grounds may be among eteachers at large.

Driving my reflections on personal experience and the enquiry reported here has been research conducted by Goleman [2], Damasio [3] and Day and Leitch [4]. In asserting that great work starts with great feeling, Goleman draws attention to the common Latin root of the words motive and emotion; motere which means 'to move'. This, he argues, supports his belief that emotions drive our motivations; emotions are what move us towards our goals. Goleman also states that motives, in turn, can be identified 
as driving perceptions and actions. Damasio declares emotion is integral to the processes of reasoning and decisionmaking, while Day and Leitch assume that teachers' emotional health is crucial to effective teaching over a career.

Synthesising Goleman, Damasio and Day and Leitch's claims above and applying them to the context of online teaching has aroused this researcher's curiosity about the part played by the affect in the motives, perceptions, actions, reasoning and decision-making of teachers whose work is largely undertaken through computer-linked modes of teaching, communication and interaction with colleagues and students. The purpose of my research has been to explore the significance of Goleman, Damasio and Day and Leitch's claims for the professional development of e-teachers whether in Higher Education or in corporate settings, and whether in blended or wholly online courses. Insofar as this Journal is aimed primarily at a corporate audience, it is my contention that even though many eteachers working in corporate settings may deploy modes of instruction that are self-contained, such as webcasts to e-learners, or design instructive environments in which elearners are largely self-paced, the findings and recommendations presented here will be of relevance to eteachers working in corporate settings who already exploit or are moving to embrace the opportunities for collaboration, creation of dynamic content and interactive information-sharing with, among and by e-learners afforded by Web 2.0 technologies. The findings may resonate also with e-teachers whose accountability in corporate workplaces rests, to whatever degree, on their effectiveness as e-teachers.

\section{CONCEPTUAL BASIS}

Ally [5] lists a number of 'benefits' of online learning for online teachers: teaching can be undertaken at anytime and from anywhere; online materials can be updated and made readily accessible to e-learners; internet connectivity provides e-teachers, and hence e-learners, with access to information that matches closely with e-learners' needs; online tools can extend e-teachers' choice when selecting and deploying diagnostic assessment instruments and can subsequently help e-teachers facilitate choice for elearners. However, e-teacher pedagogies have had to take account of the vagaries of working in an environment in which familiar language, bonds, cues, tones and relationships of face-to-face interaction have had to be modified or replaced. Consequently, e-teachers and e-learners alike have had to deal with the sense of being disconnected from others in their class [6] and, consequently, develop modes of communication and a paralanguage that can effectively replace what has been lost in moving to blended or wholly online learning. Enhanced opportunities for student collaboration afforded through computermediated communication have transformed the studenttutor relationship in e-courses, with the e-teacher's role becoming more that of facilitator than lecturer and the estudent's very much that of active learner [7]. The shift in role from content expert to learning facilitator, from an instructivist to a constructionist orientation, has brought profound changes in work patterns, activities and relationships with learners [8].

In the literature relating to the affective dimension of eteaching two concepts have been prominent: teaching presence and social presence. The concept of teaching presence has origins in Mehrabian's [9] concept of imme- diacy, which addresses the kinds of communication behaviours that enhance a sense of closeness to and nonverbal interaction with others. Anderson, Rourke, Garrison and Archer [10], writing about teaching presence in the context of what they call a 'Community of Inquiry', define teaching presence, specifically in the setting of online learning environments, as the design, facilitation and direction of cognitive and social processes for the purpose of realizing personally meaningful and educationally worthwhile learning outcomes. Clearly this view of the role of the e-teacher is more attributable to the purposes of serving the needs of the e-learner rather than to promoting professional or personal self-awareness as a pedagogue on the part of the e-teacher. Moreover, by conceptualising teaching presence under the categories of design and organisation, facilitation of discourse and direct instruction, the authors discuss teaching in computer conferencing contexts in terms of function rather than of the experience of teaching online. In none of Anderson, Rourke, Garrison and Archer's categories of teaching presence is there any explicit ascribing of the role of the affect. In contrast, Brady and Bedient [11] develop the concept of teaching presence by focusing on the relationship that teachers establish with their students: In all measures of learning, the best teachers display an ability to listen, to adapt, and to make effective choices in language and in emotions to help motivate students towards success

The related concept of social presence is introduced by communication theorists Short, Williams and Christie [12] who build on Mehrabian's concept of immediacy, defining it as the salience of the other in a mediated communication and the consequent salience of their interpersonal interactions. Developing this earlier work Rourke, Anderson, Garrison and Archer [13] assert that descriptive terms attributable to both social presence and teacher immediacy, terms such as closeness, warmth, affiliation, attraction and openness, all indicate what they call affective interaction in asynchronous, text-based, computer conferencing contexts. Garrison, Anderson and Archer [14] later simplify Short, Williams and Christie's definition of social presence as the ability of participants in the Community of Inquiry to project their personal characteristics into the community, thereby presenting themselves as 'real people'. But two aspects of this definition and hence of this concept are of particular interest. First, the research focus is on the expression of emotions rather than on the experience of feelings attached to emotions and, second, there is an absence of a research focus on the emotions, either felt or expressed, of e-teachers.

A social locus of emotions in computer-linked educational settings is focused on by Salmon [15], whose 'fivestage model of teaching and learning online' acknowledges the important role of emotions in exploiting the affordances of online learning for people to work, teach and learn together. Salmon's purpose is to draw attention to how an understanding of the impact of emotions in eteaching and e-learning can inform principles for sensitive and appropriate conference design and e-moderator's intervention and, as such, her focus is not on emotional processes of e-teachers, however, she does cite affective qualities such as motivation, intuitiveness, resilience, conscientiousness, self-awareness, interpersonal sensitivity and the ability to influence in the context of characteristics she deems to be of key importance in the recruitment of e- 
moderators. Yet experiential, psychological aspects of these characteristics are only implicit in the list of desiderata pertaining to e-teachers' functionality. Palloff and Pratt [16] similarly acknowledge the role of emotions in eteaching but their focus on exploring strategic approaches to collaboration with e-learners does not include discussion of e-teachers' experiences of feelings. Palloff and Pratt's attention to what an e-teacher can do rather than what an e-teacher can experience is echoed by Gilmore and Warren [17] who, reviewing the literature on online teaching, argue that while there is a considerable and growing corpus of literature focusing on practical issues of online teaching there is a marked absence of any acknowledgement of the emotional dimension that attends online teaching. They cite, for example, Coppola, Hiltz and Rotter [18] who see the affective role of e-teachers as primarily influencing the atmosphere of the e-classroom by attending to the relationships between the e-teacher and the e-learners and between e-learners themselves, but who also highlight a need for e-teachers to find new tools for expressing their emotions. In the face of this partial view of what it is to be an e-teacher and in the interests of developing effective, more informed and successful online teachers [19] Gilmore and Warren urge researchers to undertake further research into aspects of the emotionality of e-teaching. Although Gilmore and Warren focus on eteaching in online seminars only, my research responds in no small part to this exhortation, with the difference being that I take a much broader view of e-teaching purposes, activities and contexts.

Given the above, and if the quality of teachers' work is to be acknowledged as having any kind of bearing on the quality of the work of learners, it seemed necessary to examine the nature and roles of e-teachers' feelings in and about their work and their workplaces. My main research question emerged from this imperative: how do $e$ teachers' feelings relate to their work as e-teachers? My approach to searching for an answer was informed by three sub-questions. First, what do e-teachers feel working as e-teachers? Second, what are e-teachers conscious of when they reflect on their emotional processes as they relate to their e-teaching? The third sub-question was intended to frame the relevance of my research for eteachers' professional development as well as elicit directions for further research; what needs to be done to ensure that e-teachers experience great feelings and that great work accrues from such feelings?

\section{METHODOLOGY}

Through the metaphor of a compass Sieben [20] provides a conceptual tool for researching emotions and virtual work. Her compass brings together a range of research perspectives (poststructuralist, critical, functionalist and interpretive), facilitates reflections on different approaches and purposes of conducting research into the interplay between aspects of emotion and online work, and subsequently supports researchers as they plot a path for their work. I used Sieben's compass to select an approach that most closely suited my purposes and epistemological assumptions. Regarding the former, the core purpose of my research was to gain access to the inner worlds of e-teachers and hence to enable me to describe the phenomenon of e-teachers' consciousness of feelings in relation to working in online workplaces. Regarding the latter, my first epistemological assumption was that the knowledge I sought would emerge from analysis of my participants' subjective perspectives on, and descriptions of their inner worlds. The second was that in order to gain access to participants' affective experiences of being a teacher educator in online workplaces I had to get as close as possible to the subjective reality that participants constructed in their inner worlds. Thus, Sieben's compass helped orientate my research in an interpretive paradigm in general and, specifically, in the transcendental phenomenology of Moustakas [21] in which the phenomenon of e-teachers' experience of feelings in relation to online work is conceived as emergent and examined as situated. In other words, my research focused on subjects' feelings in relation to a particular kind of workplace. My analysis of data subsequently involved searching for features of, and relationships between feelings, online work and online workplaces that had not been uncovered in advance of my research.

Moustakas' transcendental phenomenology was especially appealing because of its central concept of intentionality and its construction of research participants as co-researchers. Moustakas explains intentionality as the internal experience of being conscious of something [22]. This appealed because of its correspondence with my desire to examine only feelings that my research participants were aware of, along with their consciousness of anything that they consider to have relatedness to those feelings. The notion of research participants as co-researchers resonated because it acknowledged the importance for me of participants remaining close to what they were describing of their experiences of the phenomenon in question so that they could deepen their understanding of and insights into their own experiences through interacting with me. This sat full-square with the aspiration that my research would be of wider value than simply providing tentative answers to my research questions.

To operationalise my epistemological assumptions I planned four phases for data gathering.

The first phase involved selecting four co-researchers (TE1, TE2, TE3 and TE4) all working in the same institution, with some sharing of e-teaching across a range of ecourses, some blended and some wholly online, and representing a range of experience in and commitment to eteaching. Brief biographical details follow. TE1: female, mid fifties; born in Scotland; teacher in Scottish secondary schools for eighteen years; teacher educator for eight years; lives alone; course coordinator of a wide range of blended and wholly online distance-learning courses; a member of a team of two online teachers working on those courses; seven years experience of working in online workplaces. TE2: male; mid forties; born in Scotland; teacher in Scottish secondary schools for seventeen years; teacher educator for nine years; lives with wife and three young children; a member of online teaching teams across a wide range of blended courses involving elearners who are either undergraduate students or college lecturers undertaking professional development through distance learning; seven years experience of working in online workplaces. TE3: female; early fifties; born in Scotland; teacher in Scottish Primary schools for twenty three years; teacher educator for four years; lives with partner; a member of online teaching teams across three blended distance-learning courses involving undergraduate students; two years experience of working in online workplaces. TE4: male; early sixties; born in Scotland; 
teacher in Scottish secondary schools for thirty two years; teacher educator for four years; lives with wife and teenage son; course coordinator on a blended distance-learning course involving undergraduate students and experienced teachers; member of a team of two online teachers working across a wide range of distance-learning courses involving experienced teachers undertaking professional development through distance learning; four years experience of working in online workplaces.

The second phase involved designing a Research Participation Guide outlining my purposes, core concepts, ethical considerations and procedures for data gathering and processing. I met with each co-researcher to contextualize and clarify the hard-copy Guide but, in light of feedback from co-researchers I subsequently augmented it by adding generic questions to aid selection and recollection of experiences and feelings, and hence support reflection.

The third phase involved me adapting the form of research interview that Zimmerman and Wieder [23] describe as a diary-interview. In my study this phase involved asking co-researchers to maintain a chronological record in the form of a series of audio recordings, made at times over a three-month period ending Christmas 2008 and in locations that suited individual co-researchers, of feelings aroused while working as e-teachers in online workplaces.. These recordings were converted to MP3 format (using Audacity) and emailed to me.

The audio recordings were transcribed and used in their own right as instruments for gathering data but also as a basis for the fourth and final phase, which was a face-toface, one-to-one, semi-structured interview with each coresearcher, conducted and recorded through March 2009. During these interviews I asked questions designed to elicit expanded commentaries on statements or longer extracts which I had selected from respective coresearchers' audio files and which I had intuited might be of particular significance to the speaker given the opportunity to reflect on them. Such questions were addressed alongside a battery of generic questions that were asked of each of the four co-researchers and which sought to explore co-researchers' experiences of the relationships between their feelings, their workplace conditions, their thought-processes, goals, motivations and coping strategies. My analysis of data followed Moustakas' procedures for transcendental phenomenological research.

At the heart of arrangements for data analysis within Moustakas' transcendental phenomenology lies a number of central concepts: first, a focus on the 'essence' or nature of a lived experience; second, that the purpose of the researcher is to produce a phenomenological description of things just as they are, in the manner in which they appear; third, that the procedures employed by the researcher will involve what Husserl [24] called the epoche or 'bracketing' the researcher's own experiences of the phenomenon.

Regarding my epoche, the first two sections of this article constitutes an abbreviated declaration of the attempt to set aside my prejudgments and prior experiences of feelings as an e-teacher working in e-workplaces. In presenting my personal experiences, my grasp of relevant emerging themes and contexts, the literature I am familiar with and my reasoning for shaping my research design as it was shaped, I have tried to re-enact the intellectual process or preparing to see, as if for the first time, what my co- researchers were experiencing. While merely writing about such things cannot accurately or convincingly replicate the act of epoche as it functions in my research it does at least draw a kind of parameter around that which could influence what I describe of co-researchers' experiences; a border that I keep a steady eye on as I work with what has been presented to me in the course of the project to date, and one that I must continue to heed as I extend the research beyond this course.

Having thus made an attempt to bracket my own experiences of the phenomenon, in order to operationalise the first two of these central concepts Moustakas proposes several procedures necessary for data analysis within this paradigm. First, data is collected from a number of people who have experienced the phenomenon; second, data are reduced to significant statements; third, significant statements are combined into themes, producing a textural description for each co-researcher and, subsequently, a combined textural description that accounts for what coresearchers experience in common; fourth, individual and combined structural descriptions of participants' experiences of the phenomenon under investigation are compiled, conveying how it was experienced with regard to the situations or contexts of those experiences; fifth, compiling the researcher's account of the essence of the experience that has been drawn from the combined textural and structural descriptions.

\section{OVERVIEW OF EMERGENT FINDINGS}

What emerges from analysis of between sixty and one hundred minutes of transcribed audio data provided by each of the four co-researchers are six inter-related themes that characterise an affective nexus between what eteachers feel in and about their e-work and their eworkplaces, and how e-teachers' feelings relate to their work in online workplaces. Of these themes three can be grouped as being informed by feelings directed towards 'other' while the remaining three are distinguished by being characterized by feelings directed towards 'self'. The first three I have categorized as the affective dimension of interaction in e-teaching, while the remaining three constitute the category I conceive as the affective dimension of being in e-teaching:

\section{A. The affective dimension of interaction in e- teaching}

A1) E-teachers' consciousness of relationships with others in e-workplaces

A2) E-teachers' consciousness of communications with others in e-workplaces

A3) E-teachers' consciousness of working with tension in e-workplaces

\section{B. The affective dimension of being in e-teaching}

B1) E-teachers' consciousness of self as e-teachers

B2) E-teachers' consciousness of professional responsibility as e-teachers

B3) E-teachers' consciousness of being reflective practitioners as e-teachers

The emergence and inter-relatedness of these themes is illustrated by sampling what co-researchers describe of their feelings as e-teachers working in e-workplaces. The statements cited below were initially identified by me dur- 
ing the initial analysis of data, and then the longer audio diary clips in which each was mentioned were replayed in full to respective co-researchers so that co-researchers could explore their personal significance more fully. What was particularly important in my research design was that each co-researcher would therefore have the final decision as to which were most representative of their experience of feelings in relation to their e-work and e-workplaces. It became very clear during the face-to-face interviews with co-researchers that replaying their audio diaries and being confronted by the timbre, inflexions, tones, pauses and varying pace of their voice was remarkably effective in evoking emotional memories. It is in this respect that the term co-researcher is most evidently vindicated since each statement and its relation to its contextualizing experiences and environments is subjected to interrogation and analysis from its author as well as by the researcher himself. Thus, the interpretations below are not idiosyncratic to this researcher. Rather, they have been jointly constructed with those who might be in the best position to say whether or not they approximate the truth or essence of the phenomenon in question.

A1): E-teachers' consciousness of their interactions with others in e-workplaces is constituted largely by their consciousness of mixed feelings related to relationships with others in online environments. For example:

- TE1 is representative of each co-researcher in that, from time-to-time, they feel joy at the commitment of e-learners: they're a keen group, there's no holding them back which is wonderful. TE1's positive feelings about student engagement energize TE1 into sustained engagement with e-learners: this must be the $3^{\text {rd }}$ or $4^{\text {th }}$ time I've checked out the sites today.

- On the other hand, when e-learners demonstrate low levels of commitment to interacting with other elearners or with course materials, as elicited through data provided by the Student Tracking tool built into WebCT, the platform on which most of each coresearchers' e-teaching is conducted, or when particular e-learners' online work is posted too late for the e-teacher to respond to it, e-teachers feelings become negatively charged. TE2 for example, declares: I'm just thinking about the frustration of working in this situation. There's a student who I haven't heard of so far or seen online yet... just posted first (assignment) and posted it very late, over a week late...and I'm in this difficult situation now where, according to the workload schedule, I've had to post my responses at a particular time...somebody comes in late so what do you do? Do you give them a personal response that nobody else has had or what? And so you're in this kind of quandary. For TE2, the central issue here is that, in comparison with the positive and productive relationships that they feel they can build with learners in face-to-face settings, the online environment presents problems: I just don't feel personally attached to this class...I've never met any of them...I don't know any of them, build no sense of who they are as human beings. They're names on the screen. I don't know anything about them and this is problematic. It's certainly problematic in terms of the nature of the responses that I feel I'm able to make to them... as a consequence the kinds of responses I am able to give are not as specific or as personal as I would like.
- TE3 echoes such feelings, commenting: I feel terribly guilty about the fact that with the online learners I'm always bumping the work that I do with them to the bottom of the list of my priorities and I think it's because I don't actually know them.

A2): E-teachers' feelings in relation to their consciousness of communications with others are unequivocally negative. For example:

- TE3 states: I think that although we try to do a good job in forming our tasks for students to do online and providing them with opportunities for wider reading, I still have this feeling that they really need to be with us face-to-face to see how we work, ways of being...opportunities for direct questions using contingent teaching to respond to questions in the moment rather than in the delay over time. This feeling of dissatisfaction impacts TE3's self-efficacy in working and communicating with e-learners: these issues are swimming around in my head and they affect...my feelings about my work and my confidence in being able to help students.

- For TE4 the perception of shortcomings in systemic aspects of e-teaching arouses feelings of inadequacy and frustration: I feel in a sense quite inadequate to deal with the volume of technological questions they have. I find the most frustrating aspect of it is the lack of control we have over the systems which the students at the other end are using whereas we may have some sort of standard in our own establishment. Although TE4 invariably does find solutions to such queries the time taken to liaise with technical support staff means less time for communicating with elearners about other aspects of their progress through the e-course and hence these negative feelings endure and diminish TE4's well-being: I really feel under pressure at the moment.

- For TE1 feelings of profound frustration are aroused over the absence of communications from one particular e-learner and this leads to TE1 perceiving that student as a dissenter and a problem. Nevertheless, TE1 is highly motivated to support e-learners and makes repeated attempts over several weeks to engage that student. Since the e-learner is also working full-time as a teacher very few opportunities for personal contact arise. TE1 reasons that the e-learner will have less pressure from daily work commitments and more time for the e-course during the school holidays and thus decides to wait until then before making a further attempt at contact. TE1's subsequent decision-making involves persisting in attempts at contact over an even longer period even though other e-courses are commencing, thus incurring an even greater workload and stress through this e-learner's ongoing lack of communication.

- For TE2 a compulsion to compare experiences and feelings in e-teaching with those of teaching in faceto-face settings brings TE2 to a position of insecurity. In face-to-face teaching TE2 feels able to make personalized responses to students that are relevant, meaningful and effective: you're aware of immediate reactions of people, you're scanning people's body language and faces. However, as an e-teacher, TE2 feels much less self-efficacious in communicating with e-learners: because there's not the immediacy of 
feedback online it does change the feeling of the work that you're doing.

- Negative feelings relating to the absence of paralinguistic cues and tones in communications within online settings are shared by both TE3 and TE1. TE3 feels inadequacy and frustration: I think it's the human touch that I feel is lacking in my style of working online because I'm working in a manner where I'm responding to students by text and they're communicating with me by text. These feelings cause TE3 to restrain the spontaneity of their own communications with e-learners: I never send off an email on first writing. I always let it sit for a while and return to it because I'm very conscious of the need to be extremely courteous and that the emails read in an extremely measured and courteous way. This written communication can be interpreted very differently to face-to-face communication. And for TE1: it's so difficult when you haven't got body language and aren't able to ask questions to clarify things online just by sending messages and texts. It's so easy to pick up the wrong inference or go off on the wrong track. To counter such misunderstandings TE1 invests even more time and effort in contacting individual elearners.

A3: Predominantly negative feelings also characterize my co-researchers' consciousness of working with tension in e-workplaces. In light of co-researchers' perceptions of their institution's lack of regard for the considerable amount of effort and number of hours that have to be invested to appropriately support e-learners, and from the fact that workload schedules take no account of those investments, co-researchers feel despondent, angered, and devalued. For example:

- TE1 confesses: I'm still smarting greatly from that carry-on with (managers) trying to load even more marking on to me. When will (managers) ever work out who does what on the staff? When will (managers) ever recognize what we do? I'm still very annoyed.

- TE2 comments: there are a number of levels of difficulties coming together to create problems in participation and how I'm feeling about wanting to participate as tutor. Certainly the lack of value placed by the (employing institution) on online discussion, and the lack of value most certainly emerges through the workload schedules that are constructed to represent what we do and these do not take account of time spent in discussion with students online.

- Among the conditions that arouse particularly negative feelings in TE2 as an e-teacher are the degree to which they feel marginalized within an e-teaching team and the degree to which TE2 feels ownership of the e-courses on which they teach. Regarding the former, TE2 states: I don't feel being an e-team member as strongly as I do being a face-to-face course team member...I feel a little bit a sense of being an individual who's working within a notional team rather than having a sense of corporate feeling of community where there's a sense of belonging at a deep level. In respect of the latter, and having been co-opted to join others e-teaching on one particular course, TE2 remarks: I'm almost a hired hand working on somebody else's course... There's certainly no sense of authorship or ownership... It's someone else's course and I'm kind of reduced to almost a bitplayer, making sporadic appearances... It's almost developing this hit-and-run mentality of not really feeling myself at the core of the practices in this course and very much on the periphery... That's not really a very comfortable place for me to be as a tutor. TE2 thus feels an outsider, that they do not belong to that e-community, that they are disempowered.

- Independence as opposed to inter-dependence seems to characterize co-researchers' e-workplaces and this adds feelings of alienation to co-researchers' ongoing anxiety about being undervalued in e-workplaces.

- For TE3 e-collegiality is an aspiration thwarted: there are shared folders, which are useful, although I sometimes feel I put material up for the good of my health because no-one (e-colleagues) looks at it, which pains me enormously.

B1: Regarding the second category of themes that can be identified as constituting an affective nexus in eteaching, the affective dimension of being in e-teaching, the theme of e-teachers' consciousness of self as-teachers can be readily elicited from what my sample of e-teachers say about themselves as e-teachers. For each co-researcher the consciousness of tension is a strong thread running through what they say about themselves. For example:

- TE4 seems to harbor feelings of grudging resignation in the following acknowledgment: I'm a teacher first and foremost and I wouldn't pretend that the online environment would be my favored choice of interaction with people. Yet for TE4 ambivalent feelings relating to being an e-teacher are expressed: like all blokes who like gizmos, which I've always done, there's a certain macho satisfaction in mastering or interacting with the system. This satisfaction seems to contribute to TE4's perseverance as an e-teacher.

- For TE3 however, the early days of working as an eteacher were attended by deep feelings of vulnerability triggered by the initial prospect of working with the technologies of the e-teacher: initially anxiety tinged with more than anxiety... a little bit of fear that I wasn't going to be able to do my job in the way that the (employing institution) might expect me to do so. And even though time has brought a degree of confidence to TE3 in working with the technologies of eteaching there is concern over having to invest even more time in upskilling to keep pace with technical innovation: its' going to take time to familiarize myself with it (new technology). You get a sinking feeling thinking, have I got time to spend hours puddling around (learning about the new technology). TE3's negative feelings about e-teaching coalesce in a metaphorical self-perception as someone who, in a domestic setting and being faced with a huge pile of ironing, feels intimidated by the effort that will have to be expended to tackle the jumbled heap in the washing basket: I feel that I'm not good at my work online. I don't do as much as I feel I should online. It's almost as if I'm really turned off by it. It's always at the bottom of my list; I put it off. It's like a big pile of ironing you've got to do that you just avoid and avoid. TE3 acknowledges that a reluctance to engage with e-learners and the e-tools of the workplace has 
ensued: I'm always bumping the work that I do with them to the bottom of the list of my priorities.

B2: Another prominent theme within e-teachers' consciousness of being an e-teacher is e-teachers' consciousness of professional responsibility. For example:

- TE1 is driven by feelings of professional responsibility: Some folk come on (to the discussion Board in WebCT) at lunchtime just for a half hour. Others...more popular...is just after school's finished, they'll maybe work for an hour or two hours then....and then there's another group who start working about this time of night...get home, get their tea, maybe do a bit of preparation for the next day and then come on and do some work. And others who might start about nine, ten o'clock at night so there's the late folk as well. You've got to be there for them all or spread yourself out and be there at the different times on different days just to... give a presence. I think that's important that you're there to answer their questions quickly because...you can't ask them to work hard, and it is hard work, for them to do these courses in their own time or weekends or evenings or their holidays on top of their normal work, so, if you're asking them to do that you've got to sacrifice a bit of yourself as well.

- To an outsider, such commitment comes at a price the risk of a work-life imbalance that could place that person in a very vulnerable position but, for TE1, this price is paid without any expression of objection: what I do on a Friday is I will probably work here till about 7 o'clock then I pick up a carry-out and usually go to a friends' house to collect my dogs...have my tea there and I'm either asleep by 9 o'clock or I'm back on the internet checking out the groups, so at some point tonight I'll go back on again and check these three sites through. And that's life for me I'm afraid. My home computer is where I do most of my work with them, particularly over the weekend.

- For TE2, forgetting to update an online assignment and judging that they have caused e-learners confusion and wasted effort, the consequent compromise to their sense of professional responsibility evokes an overwhelming sense of vulnerability and a very particular course of action related to that feeling: You're supposed to be beyond reproach, you're supposed to be a model, you're supposed to be able to demonstrate how to be organized, and clearly I wasn't doing that. And that was a real jolt to the sense of self and the emotional consequences of that were quite deep-seated. It certainly gave a knock to my confidence at that point, having to go with my tail between my legs to apologize to these people that I didn't know; didn't know how they would respond. And it had the knock-on effect in the way that I felt I was able to participate with the class in the future and it really did make me hide actually for two or three weeks.

B3: E-teachers' consciousness of being reflective practitioners as e-teachers is a theme that has emerged more through co-researchers' participation in this research study, prompted and supported through discussion with me as researcher, than through habitual introspection and unprompted disclosure. For example:
- TE1 remarks: I now realize much more through doing these tapes for you that I have been putting these students under pressure.

- After listening to one of their own audio diary clips TE2 states: That's been quite an interesting experience listening to that and thinking about it...I'll be aware of it and next time if anything like that happens I can tune in to my emotional situation with a wee bit more roundedness.

- For TE3 the experience of listening to clips from their audio diary is a very positive one: taking the time and space to do the recordings and being able to listen to what I've said... to play back what I've said has made me think about how I feel whereas before it would just have been fizzing around in my head or I feel it quite physically as well...I feel guilt very physically so it's been a feeling that's been hanging around me but taking it out into the open by putting it onto Audacity has helped me to look at it more objectively and take steps to deal with it. So it's been a useful exercise for me.

\section{Discussion OF EMERGENT FINDINGS}

Perhaps of greater interest and significance than coresearchers' consciousness of what they feel is what is emerging about their consciousness of how they feel working in online workplaces. Co-researchers are conscious of their actions, motives, reasoning and decisionmaking being influenced by and contributing to negative as well as to positive affective experiences as e-teachers. In brief, what is emerging from the data is that neither 'great feeling' nor 'great work' is experienced consistently by this small sample of e-teachers.

Through self-reflection on their experience of feelings as e-teachers, prompted by confronting their own audio diary entries and by the researcher's open questions focusing on affective aspects of what co-researchers selected as significant enough to make an audio recording about, as well as on tonal qualities of the voices making the audio recordings, co-researchers disclosed that they became conscious of feelings of disempowerment, isolation, vulnerability and frustration about and while working in eworkplaces. Further, co-researchers also became conscious that those feelings are both aroused by and impact detrimentally their sense of self as e-teachers, their participation in e-courses, their choice of e-teaching strategies, their interactions with e-learners, their relationships with others in e-workplaces and their self-efficacy as eteachers. Co-researchers disclosed that their most intense and enduring feelings, irrespective of whether they are directed at self or at other, can be uplifting and nourishing, sustaining them as e-teachers, or they can be dispiriting and enervating, provoking a lessening of commitment to or disengagement from e-teaching and the e-workplace. What also became evident to co-researchers was that over time, as e-teachers, they become distanced from aspects of being a reflective practitioner, an identifying characteristic of being a teacher working in Scottish education in the $21^{\text {st }}$ century. Three conclusions about this small sample of eteachers are thus identified:

- Co-researchers' actions, motives, reasoning and decision-making as e-teachers are influenced by their feelings about their e-work and their e-workplaces. 
- When co-researchers have little sense of themselves as e-teachers they feel deskilled, alienated and displaced as teachers.

- When co-researchers are given opportunities to develop their consciousness of being reflective practitioners as e-teachers co-researchers experience affirmative feelings that contribute to increased emotional well-being and increased commitment to eteaching.

The answer to my main research question, how do eteachers' feelings relate to their e-teaching? is, of course, a complex one that defies an easy answer but it may be simplified in a three-part response that also summarizes my responses to the first two research sub-questions. My research suggests, first, that e-teachers are conscious of their actions, motives, reasoning and decision-making as e-teachers being influenced by their feelings about their ework and their e-workplaces; second, that e-teachers' consciousness of the above cannot be assumed and that it may only enter consciousness after engaging in supported reflection with focused others who have consciously endeavored to free themselves from predisposition in order to see co-researchers' experiences as if for the first time; and, third, that negative as opposed to positive affective experiences characterize the interrelationships between cognition, motivation, behavior and emotion for eteachers whose work is situated, even in part as in teaching blended courses, in e-workplaces.

My research aimed to elicit co-researchers' descriptions of a particular phenomenon and to provide opportunities for co-researchers to reflect on what they describe of their experiences of that phenomenon. It is interesting to note that at no point in the research process did any of the coresearchers express opinions that responded to my third sub-question: what needs to be done to ensure that $e$ teachers' experience great feelings and that great work accrues from such feelings? The conceptual and practical advice about e-pedagogies offered in relevant literature undoubtedly has its place in the context of this particular sub-question however, it remains my conviction in this research to focus more on the voices and experiences of the researchers rather than on relevant academic literature. Accordingly, and in pursuit of improved workforce efficiency and increased well-being of e-teachers, my third sub-question may be answered in a number of implications prompted by my research:

1. That e-teachers routinely take into account the categories and themes of the affective nexus of eteaching when reflecting on their efficiency as eteachers and when planning their professional development as e-teachers.

2. That e-teachers commit themselves to collaborating with impartial others in the development of their professional self-reflections.

3. That e-teachers consider developing their knowledge and understanding of techniques of emotion regulation.

My research also elicits implications for e-teachers' managers:

1. That managers ensure e-teachers are supported in reflecting on not just what they do as e-teachers but also on how they feel about their e-workplace conditions and what they do as e-teachers in those eworkplaces.
2. That managers ensure the induction of e-teachers into e-teaching, and their ongoing professional development includes consideration of affective aspects of what it is to be an e-teacher as well as affective aspects of what it is to interact with others in eworkplaces.

3. That managers adopt a strategic approach to embedding the affective nexus of e-teaching into eworkplace culture, practices and values.

Hargreaves' [25] conviction that educational reform will be impeded and fundamental aspects of teachers' work damaged if leadership strategies do not give due attention to teachers' emotions, resonates loudly from my findings, regardless of the fact that Hargreaves was not speaking about e-learning and e-teaching specifically. It also seems that Day and Leitch's [4] concerns about the impact of teachers' emotional health on the effectiveness of their teaching have more than a passing relevance to the emotional well-being of the e-teachers who participated in my research.

If the findings about the affective nexus of e-teaching reported here are to prove valid, reliable and have credibility across a range of corporate e-workplaces and organizations, the addition of significantly more data from an increased number of co-researchers must be secured. The significance of factors such as co-researchers ethnic origins, age, gender, personality type, employing organization and country in which they work will each also have to be examined if the limitations of this study are to be addressed. Further, a longitudinal study of co-researchers careers as e-teachers unfold would contribute much to the knowledge-base of the affective nexus of e-teaching.

This research suggests that neither 'great feelings' nor 'great work' are experienced consistently by the small sample of e-teachers. What has been identified as the affective nexus of e-teaching thus signals new foci for the personal and professional development of e-teachers, and new foci for managers of e-teachers. In these troubled economic times the effectiveness of teaching and learning in general, and e-teaching and e-learning in particular can, much more than in recent history, be key factors in economic survival. Further research into an affective nexus in e-teaching in corporate settings is thus recommended. The inherent challenges have to be accepted by researchers in both the academic and corporate worlds.

\section{REFERENCES}

[1] A. Damasio, The Feeling of What Happens, Vintage, London, 2000, p. 36.

[2] D. Goleman, Working with Emotional Intelligence, Bloomsbury, London, 1998, p. 106.

[3] A. Damasio, The Feeling of What Happens, Vintage, London, 2000, p. 41.

[4] C. Day and R. Leitch, "Teacher and teacher educators' lives: the role of emotion,” Teaching and Teacher Education, vol. 17, no. 4, p403, 2001. (doi:10.1016/S0742-051X(01)00003-8)

[5] M. Ally, "Foundations of educational theory for online learning," in T. Anderson, (Ed), The theory and practice of online learning, $2^{\text {nd }}$ ed., Edmonton, AU press, Athabasca university, 2008, p5.

[6] M. Bullen, "Participation and critical thinking in online university distance education,” Journal of Distance Education, vol. 13, no. 2, 2, pp. 1 - 32, 1998.

[7] L. N. Harasim, S. R. Hiltz, L. Teles and M. Turoff, Learning Networks: A field guide to teaching and learning online. Cambridge, MA: The MIT Press, 1995. 
[8] K. L. Murphy, S. E. Mahoney, C. Y. Chen, N. V. Mendoza-Diaz and $\mathrm{X}$. Yang, "A constructivist model of mentoring coaching and facilitating online discussions, Distance Education, vol. 26, no. 3, pp. 341 - 366, 2005. (doi:10.1080/01587910500291454)

[9] A. Mehrabian, "Some referents and measures of nonverbal behavior," Research Methods and Instrumentation, vol. 1, no. 6, 1969.

[10] T. Anderson, L. Rourke, D. R. Garrison and W. Archer, "Assessing teaching presence in a computer conferencing context," Journal of Asynchronous Learning Networks, vol. 5, no. 2, pp. 1 - 17, 2001.

[11] E. Brady and D. Bedient, "The effects of teacher presence on student performances and attitudes,” WebCT Impact 2003, $5^{\text {th }}$ Annual WebCT User Conference, 2003. Available http://booboo.wbct.com/2003/papers/Brady.pdf $\quad$ Accessed 18/04/06

[12] J. Short, E. Williams and B. Christie, The Social Psychology of Telecommunications, Toronto, ON: Wiley, 1976, p. 65.

[13] L. Rourke, T. Anderson, D. R. Garrison and W. Archer, "Assessing social presence in text-based, asynchronous computer conferencing," Journal of Distance Education, vol. 14, no. 3, pp. 51 70, 1999.

[14] D. R. Garrison, T Anderson and W. Archer, "Critical inquiry in a text-based environment: computer conferencing in higher education," The Internet and Higher Education, vol. 2, no. 2-3, p. 94, 2000. Available http://communitiesofinquiry.com/documents/ CTinTextenvFinal.pdf Accessed 18/02/09

[15] G. Salmon, $2^{\text {nd }}$ ed., E-moderating: the Key to Teaching and Learning Online, London, Routledge Falmer, 2004, pp. 32 - 37.

[16] R. M. Palloff and K. Pratt, Collaborating online: Learning together in Community, San Francisco, Jossey-Bass, 2005.

[17] S. Gilmore and S. Warren, "Emotion online: Experiences of teaching in a virtual learning environment," Human Relations, vol. 60, no. 4, pp. 581-608, 2007. (doi:10.1177/0018726707078351)
[18] N. W. Coppola, S. R. Hiltz and N. G. Rotter, "Becoming a virtual professor: pedagogical roles and ALN," cited in S. Gilmore and S. Warren, "Emotion online: Experiences of teaching in a virtual learning environment," Human Relations, vol. 60, no. 4, p. 586, 2007.

[19] S. Gilmore and S. Warren, "Emotion online: Experiences of teaching in a virtual learning environment," Human Relations, vol. 60, no. 4, p. 604, 2007. (doi:10.1177/0018726707078351)

[20] B. Sieben, "Doing research on emotion and virtual work: A compass to assist orientation" Human Relations, vol. 60, no. 4, pp. 561-580, 2007. (doi:10.1177/0018726707078347)

[21] C. Moustakas, Phenomenological Research Methods, Thousand Oaks, CA: Sage, 1994.

[22] C. Moustakas, Phenomenological Research Methods, Thousand Oaks, CA: Sage, 1994, p. 28.

[23] D.H. Zimmerman and D. Wieder, 2The diary-interview method", Urban Life, vol. 5, no. 4, pp. 479-498, 1977.

[24] E. Husserl, Ideas: General Introduction to Pure Phenomenology, London: George Allan and Unwin, 1931.

[25] A. Hargreaves, "The emotional politics of teaching and teacher development: with implications for educational leadership", International Journal of Leadership in Education, vol. 1, no. 4, pp. 315-336, 1998. (doi:10.1080/1360312980010401)

\section{AUTHOR}

Kenny McIntosh is a lecturer in Language Education with the School of Education, University of Aberdeen, Scotland (e-mail: k.j.mcintosh@abdn.ac.uk ).

Manuscript received July 5th, 2009. Published as resubmitted by the author February $2^{\text {nd }}, 2010$. 